\title{
A PROGRESS REPORT FOR RESEAKCH ON
}

\section{DISLOCATION-SOLUTE ATOM INTERACTIONS IN ALLOYS}

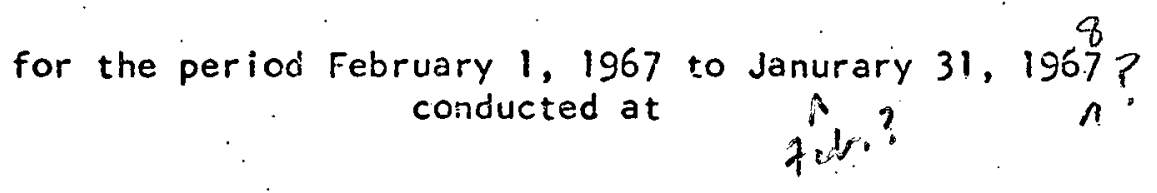

The Department of Metallurgy

Case Western Reserve University

Cleveland, Ohio 44106

In comoperation with

The United States Atomic Energy Commission

Contraci No. $(11.1)-1676$

Prepared by

R. Gibala, Principal lnvestigetor

F. Povolo

M.G, Ul itchriy

K.V. Ràvi

October $3 i, 1967^{\sim}$

\section{LEG $\widehat{A L}$ NOTICE}

Conited This report was prepared as an account of Government sponsored work. Neither States, nor the Commission, nor any person acting on behaif of the Com th respect to the accuA. Makes any warranty or representation, expressed or implied, wh report, or that the use racy, completeness, or usefulness of the information contained in this report may not infringe of any information, apparatus, method, or process disclosed in this report may not infriage privaty a ned tisto;

pesect to the use or for damages resulting from the B. Assumes any liabiltiras wethed, or process dlsclosed in this report. As used in the above. "person acting on behalf of the Commisston" to the extent that ployee or contractor of the Commisslon, or employee employee of such contractor prepares, such employee or contractor of the Commission, or emplont to his employment or contract disseminates, or provides access to, any information pursuant

with the Commission, or his employment with 


\section{DISCLAIMER}

This report was prepared as an account of work sponsored by an agency of the United States Government. Neither the United States Government nor any agency Thereof, nor any of their employees, makes any warranty, express or implied, or assumes any legal liability or responsibility for the accuracy, completeness, or usefulness of any information, apparatus, product, or process disclosed, or represents that its use would not infringe privately owned rights. Reference herein to any specific commercial product, process, or service by trade name, trademark, manufacturer, or otherwise does not necessarily constitute or imply its endorsement, recommendation, or favoring by the United States Government or any agency thereof. The views and opinions of authors expressed herein do not necessarily state or reflect those of the United States Government or any agency thereof. 


\section{DISCLAIMER}

Portions of this document may be illegible in electronic image products. Images are produced from the best available original document. 


\section{A PROGPESS REPORT FOR RESEARCH ON DISLOCATIONOSOLITE ATOM INTERACTIONS IN ALLOYS}

Three projects suggested in the original proposal to the AEC were undertaken in part or in total during the past year. The progress on these projects is reported herein.

1. Dislocation-Interstitial Solute Interaction in Ciose-packed Metals. (Investigators - M.G. Ulitchny, R. Gibala)

A program for investigation of dislocation-interstitial solute interactions in close-packed metals by utilizing the anelastic behavior of the interstitial solid solutions was undertaken at the beginning of the present contract period. Face-centered cubic iron-nickel alloys doped with carbon were chosen for initial studies because of the known existence of substitutional - interstitial (swi) interaction relaxation peaks in these materials $(1)$ and the availability, in part, of mechanical properties studies associated with the effects of interstitials. (2,3) Âlloys of high nickel contents (\$3 35 at.pct.) were chosen because of their low.M. and $M_{d}$ temperatures. ${ }^{(4)}$ The alloys have been obtainsd in rod form of two purity levels: commercial Invar, which is nomina!ly 36 at.pct.Ni, and high purity Fe-36\% castings $\left(99.9^{+}\right.$Fe and $\left.\mathrm{Mi}\right)$, and have been swaged and drawn to $0.025 \mathrm{in}$. to $0.040 \mathrm{in}$. wires.

The main effort in the first eight monihs of work on this project has been in designing, building and perfecting a high temperature (roon temperature to $1200^{\circ} \mathrm{K}$ ) vacum torsion pendulum required for the srelas ticity experiments. The pendulum, shown in figure 1, is a modified version of a design developed by Peters. (5) Also built during the prem sent contract period was a gas train and furnace system for conirolled addition of carbon to the Fewili alloys. This work has now been completed, 
and preliminary data are being obtained. At present, we have only conm firmed the existence of the $s-i$ interaction peak observed by $W u$ and Wang, ( 1 ) which we will use as a measure of the amount of interstitials in solution, See Figure 2: Strain-aging and precipitation experiments are in progress, and definitive results are expected before the end of the present contract period. We anticipate being able to establish the existence of a carbondislocation interaction (i.e. cold-work) peak, similar perhaps to ones observed for hydrogen in austenitic steels. (5)

An important aspect of this problem will involve comparison of the results in fcc metals with their counterparts in the more well-established studies of bcc metais. (7) Because the mechanism of the cold-work peak (CWP) is still not well established in bcc metals, we have examined critically the investigations on bcc metals as part of the past year's activities on this project. Our present feelings are essentially unchanged from that indicated in a recent publication, (8) that a mechanism involving vibrating dislocations which drag their attendant interstitial atmospheres with them best describes the physical situation. Of considerable importance to future work on the CWP, we feel, will be experiments which relate the dislocation distributions deterninable by transmission electron microscopy to the relaxation parameters of the CWf. $(9,10)$ our views are expressed in a paper submitted to and accepted by Scripta Metallurgica, as part of this project. Preprints listed as Report No. C00-1676-2 are included with this progress report.

11. Solute Partitioning and Its Effecis on Strengthening in BCC Refractory Metals (investigators - K.V. Ravi, R. Gibala)

An experimental program to study interstitial hardening and the effect of interstitial partitioning (in solution, precipitated, defect-essociated, etc.) 
on the hardening has been initiated in September, 1967 of the present contract period. The niobium-oxygen and niobium-nitrogen systems have been chosen for investigation because of their terminal solid solubility behaviors are reasonably well understood. We have decided that the base material for the study will be zone-refined and vacuum outgassed $\left(10^{-8}\right.$ to $10^{-9} \mathrm{~mm} \mathrm{Hg}$ ) niobium single crystals. Preliminary studies (see section III) have indicated that these materials have very low residual interstitial levels. Addition of interstitials in controlled amounts will be accomplished either by a volumetric technique (11) or by diffusion annealing of deposited anodic films. (12). These techniques are being perfected at present. We anticipate initial results on hardering behavior by the end of the present contract period.

A necessary corollary to this study is the investigation of the nature of interstitial solute partitioning processes in bcc metals, including solubility, solute-solute interactions, solute-dislocation interactions, etc. To this end, a large part of Professor Gibala's activity associated with this project has been in the assembly and writing of a review paper entitled tenatively "Incerstitials in the BCC Metals". The paper is being comauthored with Professor C.A. Wert of the University of Illinois. Preprints of the paper are included with the progress report as Report No. C00-1676-3. Selected topics from the paper will be presented as an invited talk at the Annual Meeting of the Metallurgical Society of AlME in February, 1968. A slight shortened and revised version will appear in the many-volumed series Energetics of Metaliurgical Phemonema.

111. Dislocation-Substitutional and - Interstitial Interaction in 8CC Metals (Investigators - F. Povolo, R. Gibala).

Dislocation - solute atom interactions in the bcc refractory metals 
are being investigated by study of the temperature and concentration dependence of amplitude dependent (hysteretic) internal friction due to dislocations. (13) Present experiments are being conducted on niobium and dilute niobium-base alloys (molybdenum, vanadiun, and zirconium as solutes).

Internal friction in these experiments is measured by the Marx threecomponent piezoelectric technique, ${ }^{(14)}$ in a method similar to that employed by Fiore and Bauer. (15) The equipment is shown in Figure 3. The main feature of this set-up is its valve-less construction, which permits measurements in a vacuum of better than $10^{-6}$ torr at the furthest point from the pumping system. Modifications being planned will lower the ultimate vacuum to $10^{-8} \mathrm{~mm} \mathrm{Hg}$. during measurements. The same system with a modified head (Figure 4) is used to vacuum outgas previously zone-melted specimens near the melting point in vacuums of $10^{-8}$ to $10^{-9}$ torr. The need for the high vacuum will be evident from the discussion below.

The results obtained thus far are best given summarily in chronological order. Earliest studies were made on single crystals of $\mathrm{Nb}$ and $\mathrm{Nb}-\mathrm{V},-\mathrm{MO}$, and-Z̈r binary alloys ( $\leqslant 1$ at.pct: solute) which were zone-melted by usual techniques (vacuum of $\sim 10^{-5}$ torr, zone speeds of approximately $20 \mathrm{in}$. per minute). Figure 5 shows typical internal friction results on these materials. In both the pure metal and alloys there is only a siight amplitude dependence of the dislocation damping at all temperatures and then only at the highest attainable amplitudes. There are also no clear differences in the damping behavior of either the metal or the alloys as far as magnitude, "breakaway" amplitude, slope of the amplitude dependent damping, etc.

It became clear from such results that residual interstitial levels were dominating the observations. Thus long time, high temperature solid state vacuum outgassing of the zone-melted specimens was urdertaken 
in an attempt to further purify the base materials. The effect of the outgassing treatments - a substantial decrease in breakaway amplitude. and an increase in the slope of the amplitude dependent damping-is shown in Figure 6 for a $\mathrm{Nb}-1 \% \mathrm{Zr}$ alloy and indicates the success of the treatments. Similar results were obtained for unalloyed $\mathrm{Nb}$ and $\mathrm{Nb}-\mathrm{V}$. alloys so that the results can not be attributed to zone refining of the substitutional solute; nevertheless, this is an important experimental problem.

The effect of temperature, which should redistribute the solute atoms to and from dislocation sites, was observed to be complex. Over the temperature range $23^{\circ} \mathrm{C}$ to $800^{\circ} \mathrm{C}$, increasing the temperature, which should rarefy the solute atmospheres at dislocations, generally had the expected effect of decreasing the breakaway amplitude and increasing the slope of the amplitude dependent damping. Figure 7 shows such results for a nominal $\mathrm{No}-1 \% \mathrm{~V}$ alloy over a limited temperature range. Similar results are reflected in the data given in Figure 8 for pure $\mathrm{Nb}$. Here the amplitude dependent damping is plotted to according to the form suggested by the Granato-Lucke theory. (13) According to the theory, the plots of $\ln \left(Q_{H}^{-1} \cdot E_{0}^{\frac{1}{2}}\right)$ vs $1 / E_{0}$ (where $Q_{H}^{-1}=$ amplitude dependent damping and $E_{0}=$ strain) should be straight lines. The slopes should increase as the solute atmospheres at dislocations rarefy with increasing temperature. That the plots are not straight line in almost all cases makes detailed analysis of the results in terms of the dislocation - solute interaction processes operating difficult at present. From the complicated effects of temperature over the entire range investi: gated, it appears that more than one pinning process (with different temperature dependences) are operating and that the damping must be described as a sum of Granato-Lucke processes, as a sum of modified Granato-Lucke processes, ${ }^{(16)}$ or perhaps by a different model al together. 
At this preliminary stage in the investigation, we can not say for sure how the data should best be analyzed. However, it is clear that a model perhaps different in detail from the unmodified Granato-Lucke theory might be necessary. One very striking observation has evolved from the observations thus far. This is that while the amplitude dependent damping is not adequately described by the Granato-Lucke approach, it is accurately described by a simple linear law, i.e. $\varphi_{H}^{-1}$ is proportional to $\epsilon_{0}$. In cases where the damping is not strictly linear, it is then closely given by a sum of two straight lines. Typical data for unalloyed Nb are shown in Figure 9. Data obtained on the dilute alloys are similar.

The unusual changes in the slopes of the damping curves with temperature should be noted. While we are unsure of the interpretation of these effects at present, we point out that (1) they indicate substantial re. shuffling of pinning points is occurring with increasing temperature, and (2) the effects are apparently related to the positions of the oxygen and nitrogen Snoek peaks in niobium. (17)

In summary, research on this project has thus far established the

\section{following:}

1. Substitutional solutes have only minor effects on the dislocation damping in bcc refractory metals, even after extended purification treatments, compared to residua? intersitials.

2. The clașsical Granato-lucke theory does not adequately deseribe the strain amplitude dependence of the dislocation damping.

3. A linear dependence of damping on strain amplitude best characterizes the results on $\mathrm{Nb}$ and some of its dilute substitutional alloys.

4. The temperature dependence of the amiplitude dependent damping shows the effect of at least two stages of pinning over the range $23^{\circ} \mathrm{C}$ to $800^{\circ} \mathrm{C}$. 
The aim of this project in the coming year is three-fold:

(1) to extend the measurement described above to temperatures below room temperature,

(2) to establish as a baseline the dislocation damping associated with residual interstitials in the unalloyed niobium, and then

(3) to follow through with measurements on the dilute. alloys to establish better the role of the substitutional solutes in the pinning processes.

We expect results on the unalloyed niobium to be in a form ready for publication by the end of the coming year.

In summary for the entire research program during the present contract period, we can say the following:

1. All of the originally proposed projects have been initiated, however not all of them from the inception of the contract on February 1, 1967. The reason was simply that not enough acceptable prospective graduate assistants were available from the beginning of contract period.

2. In some instances, the scope of the individual projects was exponded or complemented, mainly through written papers based on critical examination of the technical literature.

3. With the exception of the problem of the initial unavailability of a graduate assisiant for work on one of the three experimental projects (no. Il above), all of the proposed projects have proceeded closely to the anticipated time schedule given in the original proposal. 


\section{BIBLIOGRAPHY}

1. T.L. Wu and C.M. Wang, Sci. Sinica (Peking) I, 1029 (1958).

2. K.S.B. Rose and S.G. Glover, Acta Met. 14, 1505 (1966).

3. G.V. Smith, in the Annual Report of the Materials Science Department, Cornell University, 1966.

4. L. Kaufmann and M. Cohen, Progress in Metal Physics Vol. 7, p. 165, Pergamon Press, New York (1958).

5. D.T. Peters, Ph.D. Thesis, Ohio State University, 1962.

6. J.A. Peterson, R. Gibala, and A.R. Troiano, J. Appl. Phys. 38, 1992 (1967).

7. See for example D.P. Peterra and D.N. Bestiers, Acta Met 15, 791 (1967).

8. R. Gibala, Acta Met. 15, 428 (1967).

9. M.L. Rudee and R.A. Huggins, Trans. AIME 236, 1662 (1966).

10. H. Ino and.T. Sugeno, Acta Met. 15, 1197. (1967).

11. J.R. Cost and C.R. Wert, Acta Met: 11, 1313 (1963).

12. C.S. Tedmon, Jr., R.M. Rose, and J.Wulff, Trans. AIME 230, 1732. (1964).

13. A. Granato and K. Lucke, Physical Acoustics-Principles and Methods, Vol IV-A, Academic Press, New York (1966).

14. J. Marx, Rev. Sci. Instr. 22, 503 (1951).

15. N.F. Fiore and C.L. Baver, Acta Met. 12, 1329 (1964).

16. See for example J. Friedel, The Relation Between the Structure and Mechnaical Properties of Metals, P. 410, H.M.S.0., London (1964).

17. R.W. Powers and M.V. Doyle, J. Appl. Phys. 30, 514 (1959).

Technical Reports, Articles Prepared for Publication, etc. (See appended material.)

\section{PREPR INTS}

1. "Comments on 'The Cold-Work Peak in Alpha Iron", by R. Gibala, Accepted for publication by Sciripta Neta!lurgica. 
2. "Interstitials in the $8 C C$ Refractory Metals," by R. Gibala and C.A. Wert, to appear in Energetics of Metallurgical Phenomena. (University of Denver. Summer Lecture Series, 1966.) 


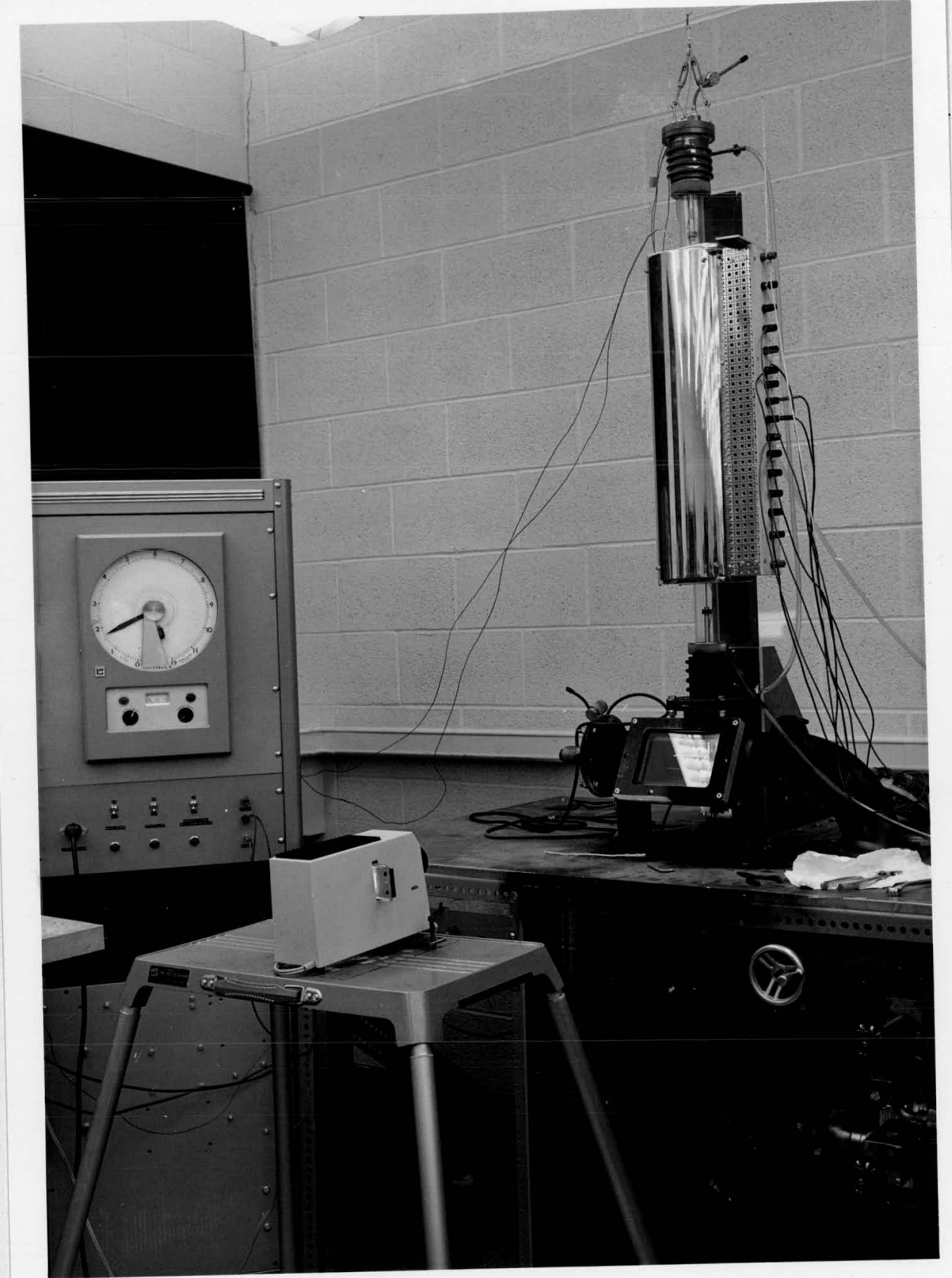

Figure 1. Photograph of the high temperature vacuum torsion pendulum used in experimental studies of cold-work peaks. 

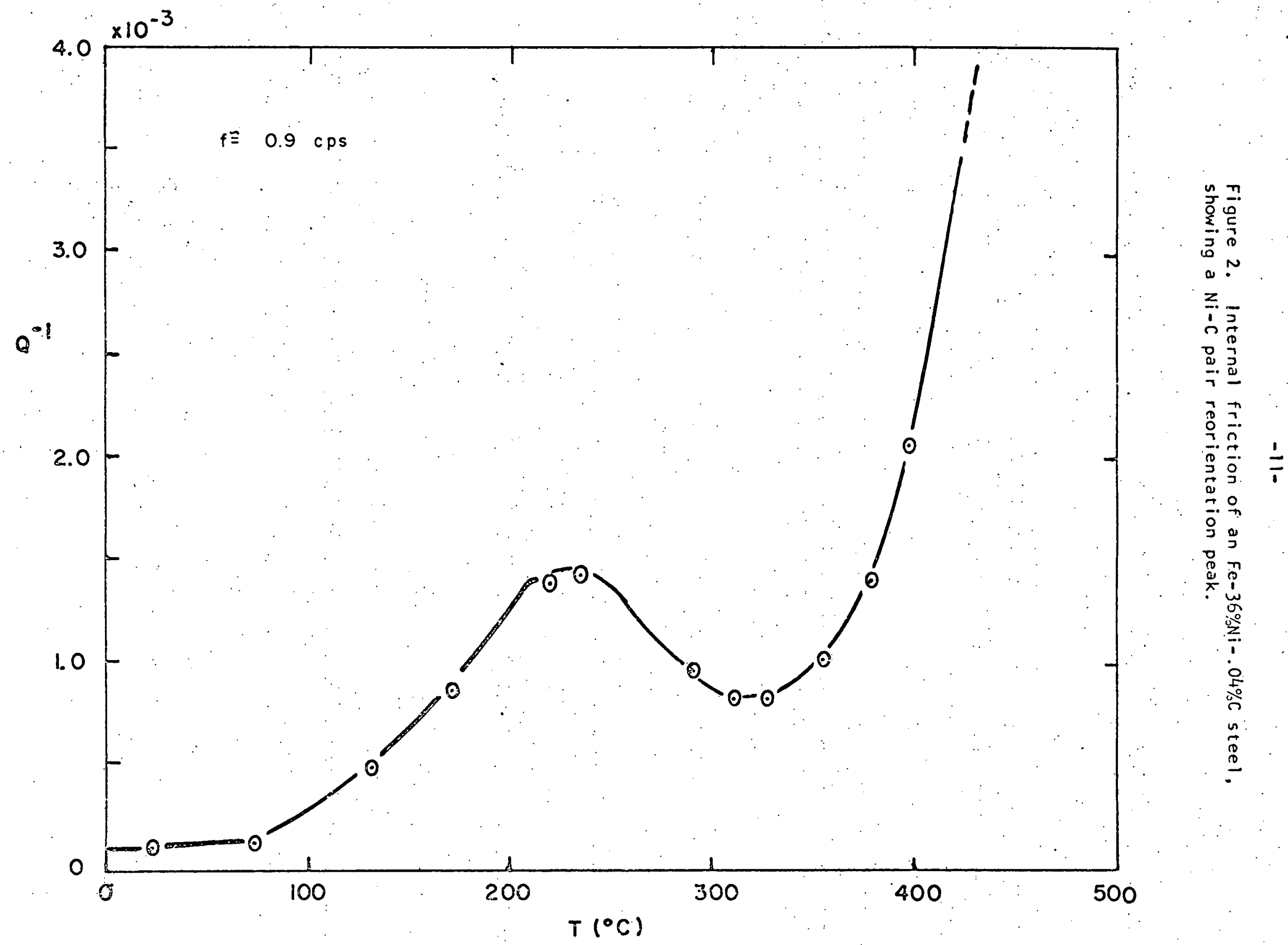


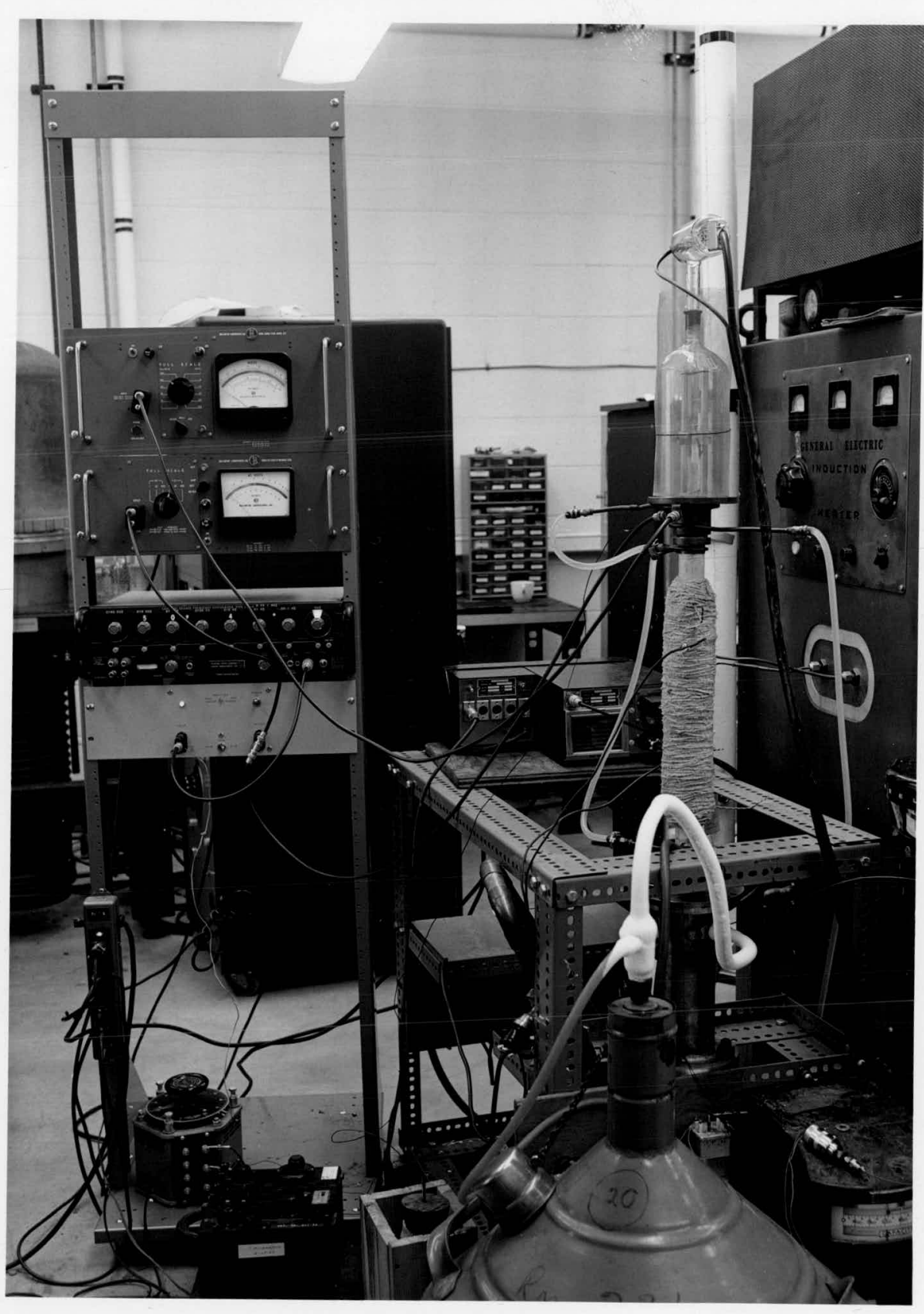

Figure 3. Photograph of the equipment for measuring internal friction in the khz range in vacuums of $10^{26}$ torr and lower. 
Figure 4. Adaption of the equipment shown in Figure 3 for high temperature vacuum outgassing of bcc refractory metals.
$A=$ SPECIMEN ON CERANIC HOLDER
$B=$ HIGH FREQUENCY INDUCTION COIL
$C=$ WAX JOINTS
D = IONIZATION GAUGE
$E=L I Q U I D \cdot N_{2}$ TRAP
$F=B A F F L E$
$G=$ TO LIQUID $N_{2}$
$H=$ DIFFUSION PUMP
$1=$ TO MECHANICAL PUMP

ALL. GLASS CONSTRUCTION BEYOND BAFFLE

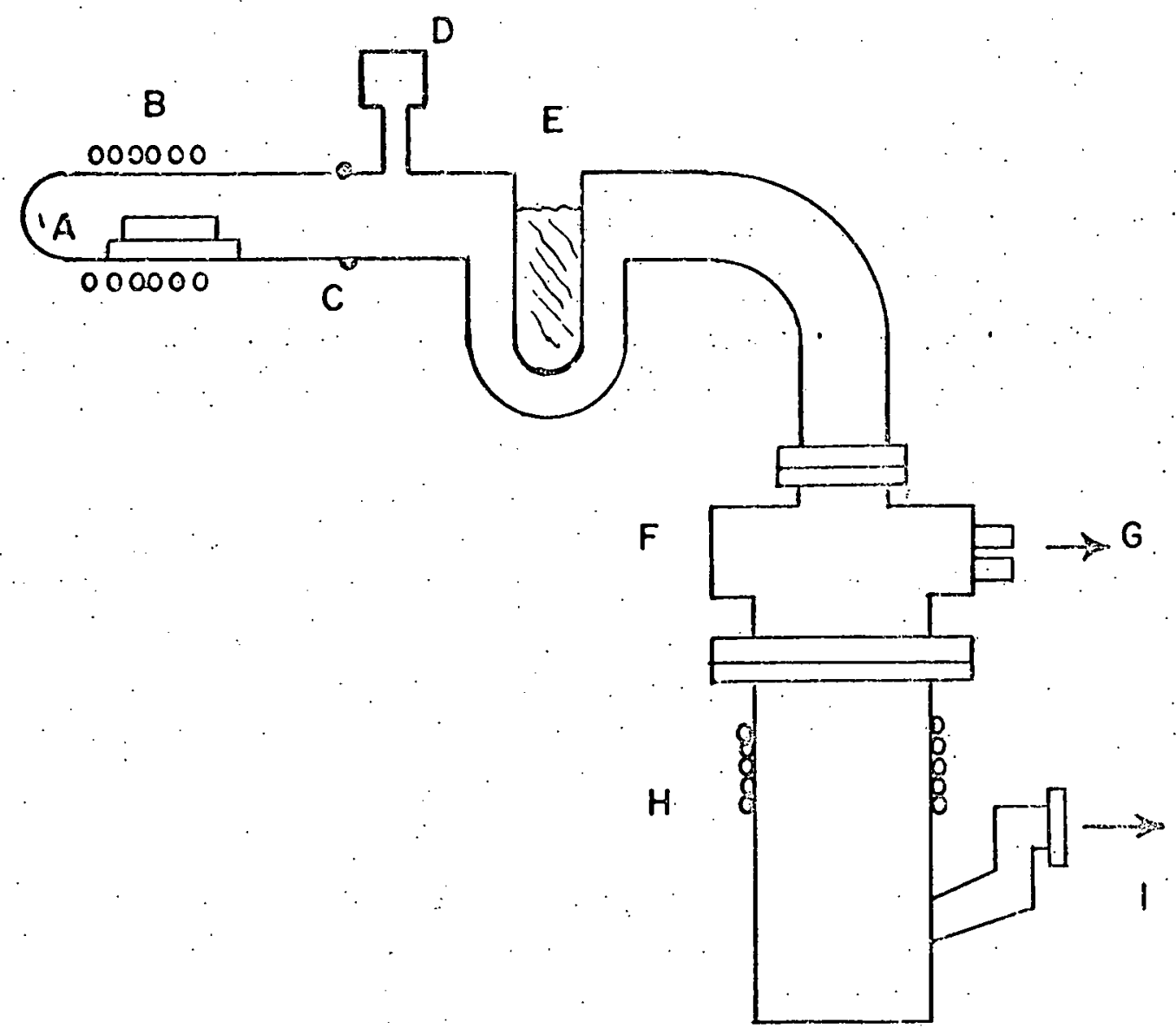




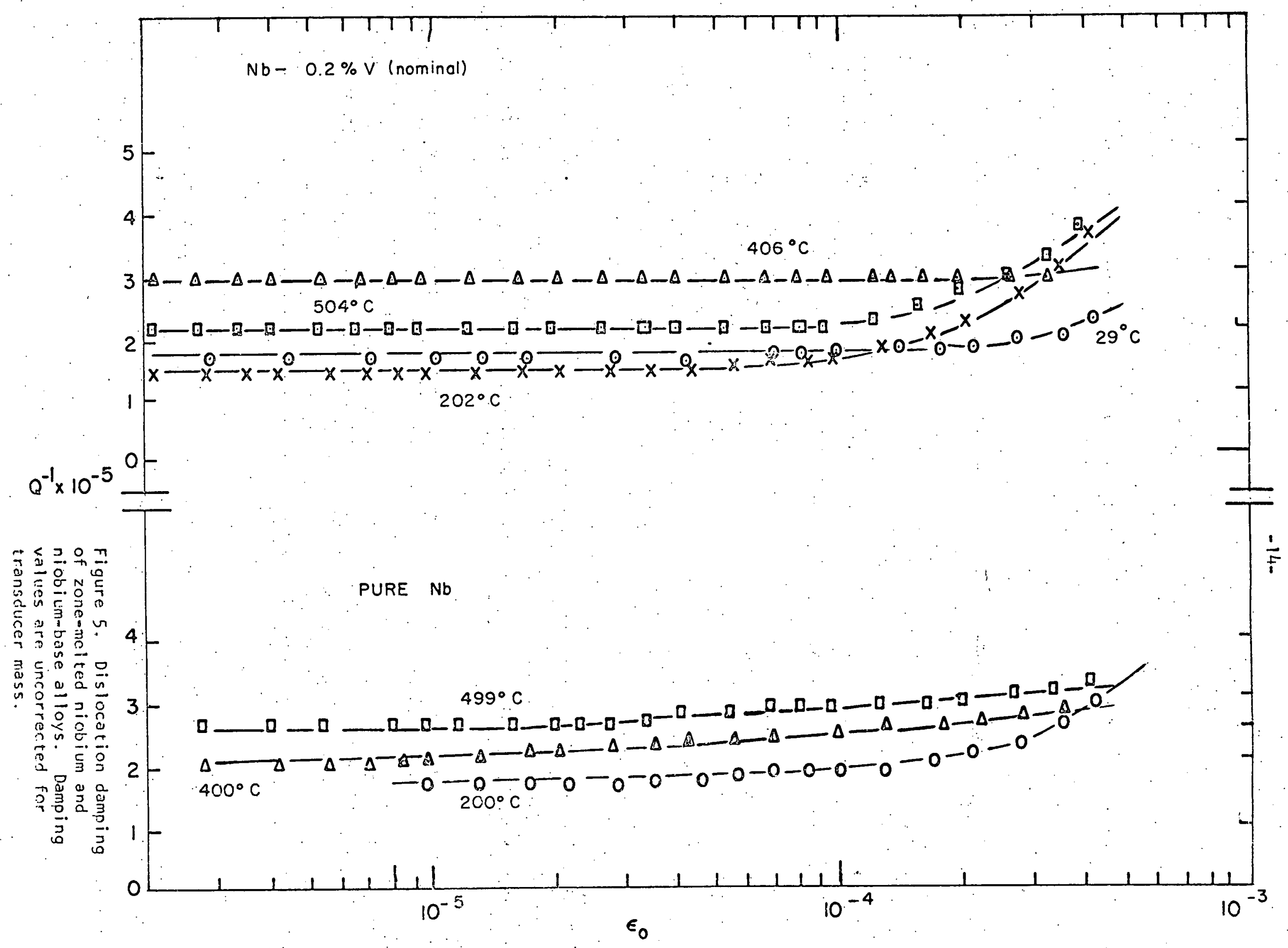




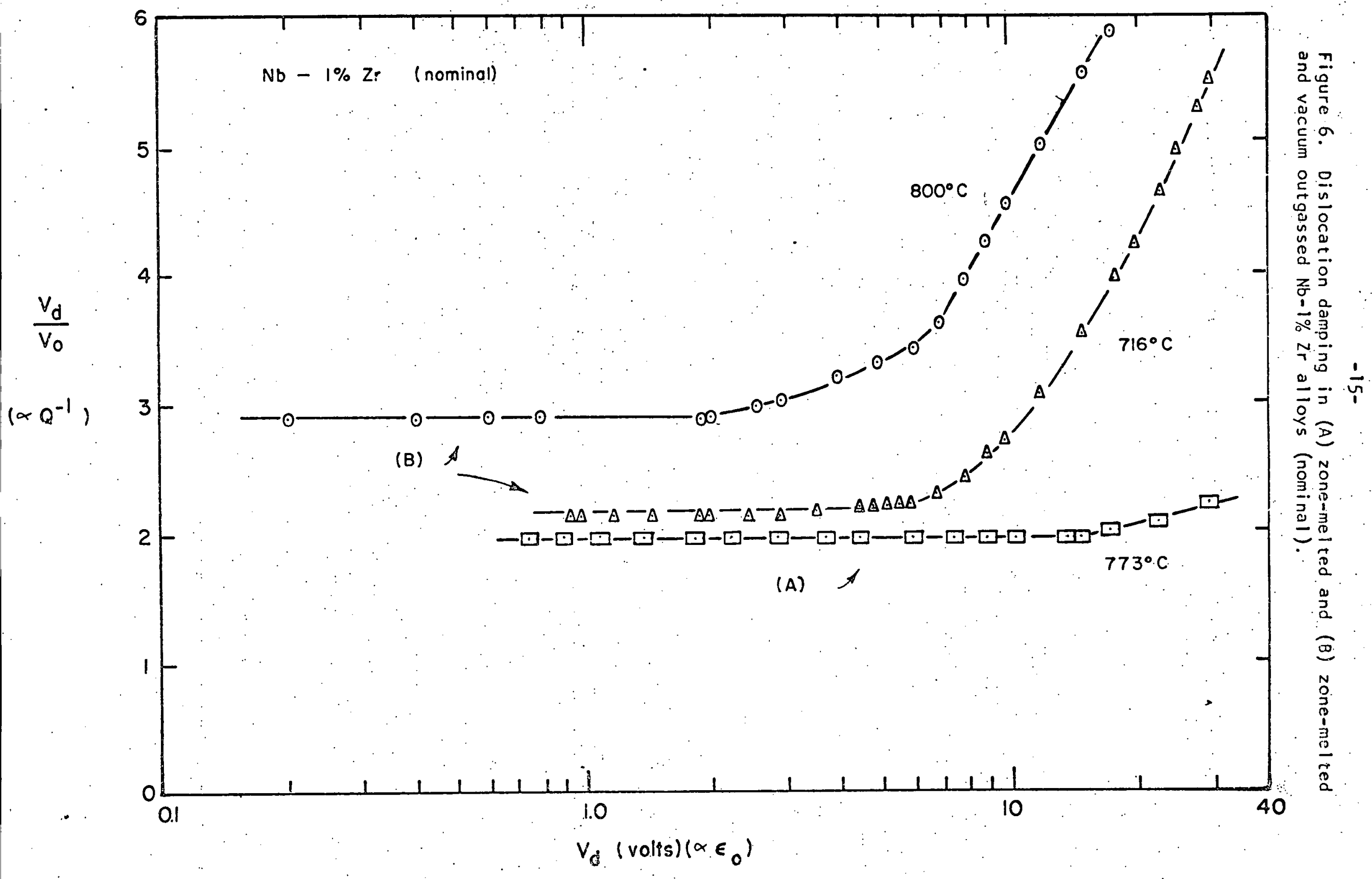




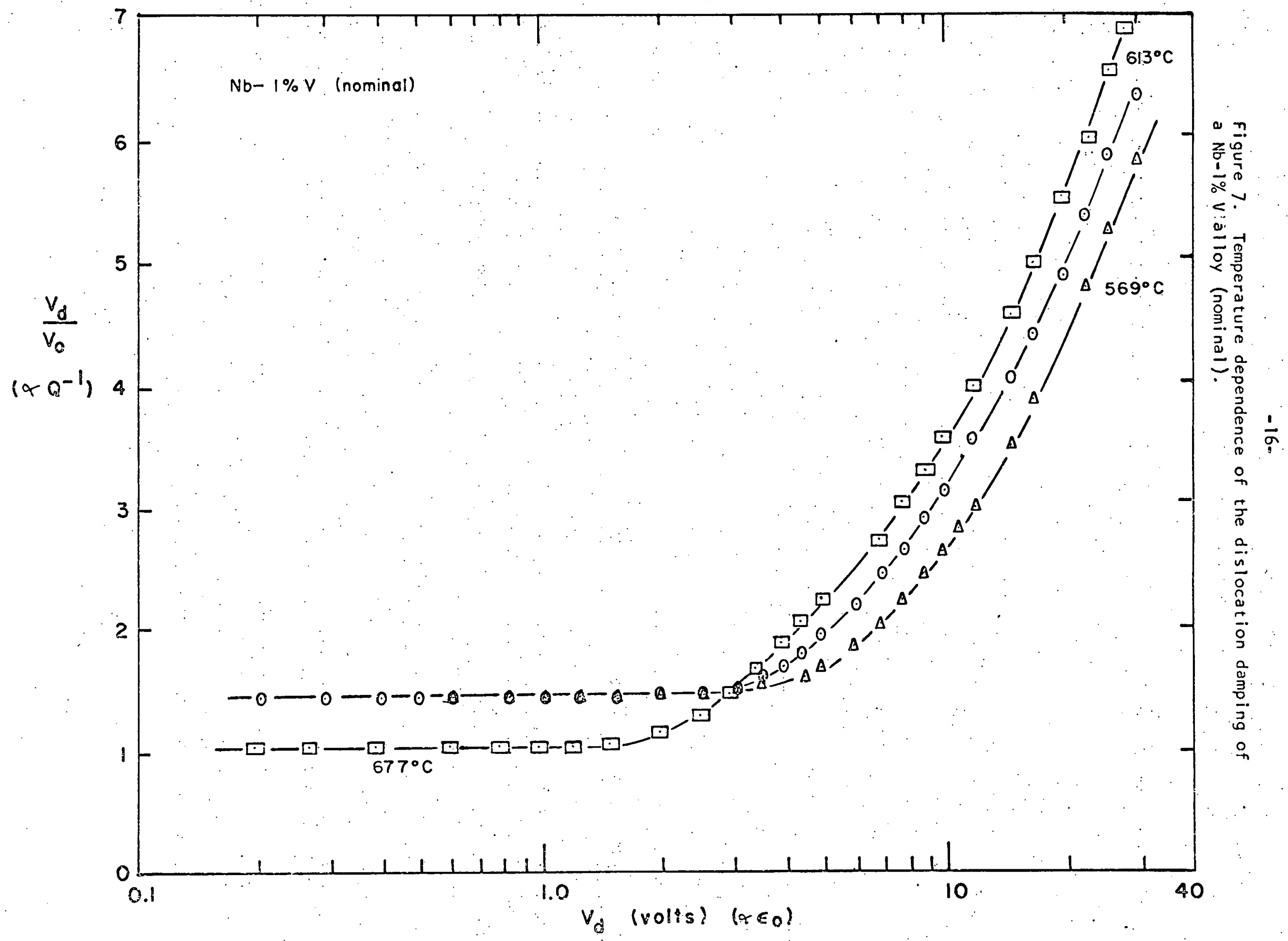




$$
-1 \%-17-
$$

Figure 8. Temperatue deperidence of the dislocation damping of unalloyed Nb. The data are plotted according to the Granato-Lucke theory. (13) Temperatures are in ${ }^{\circ}$.

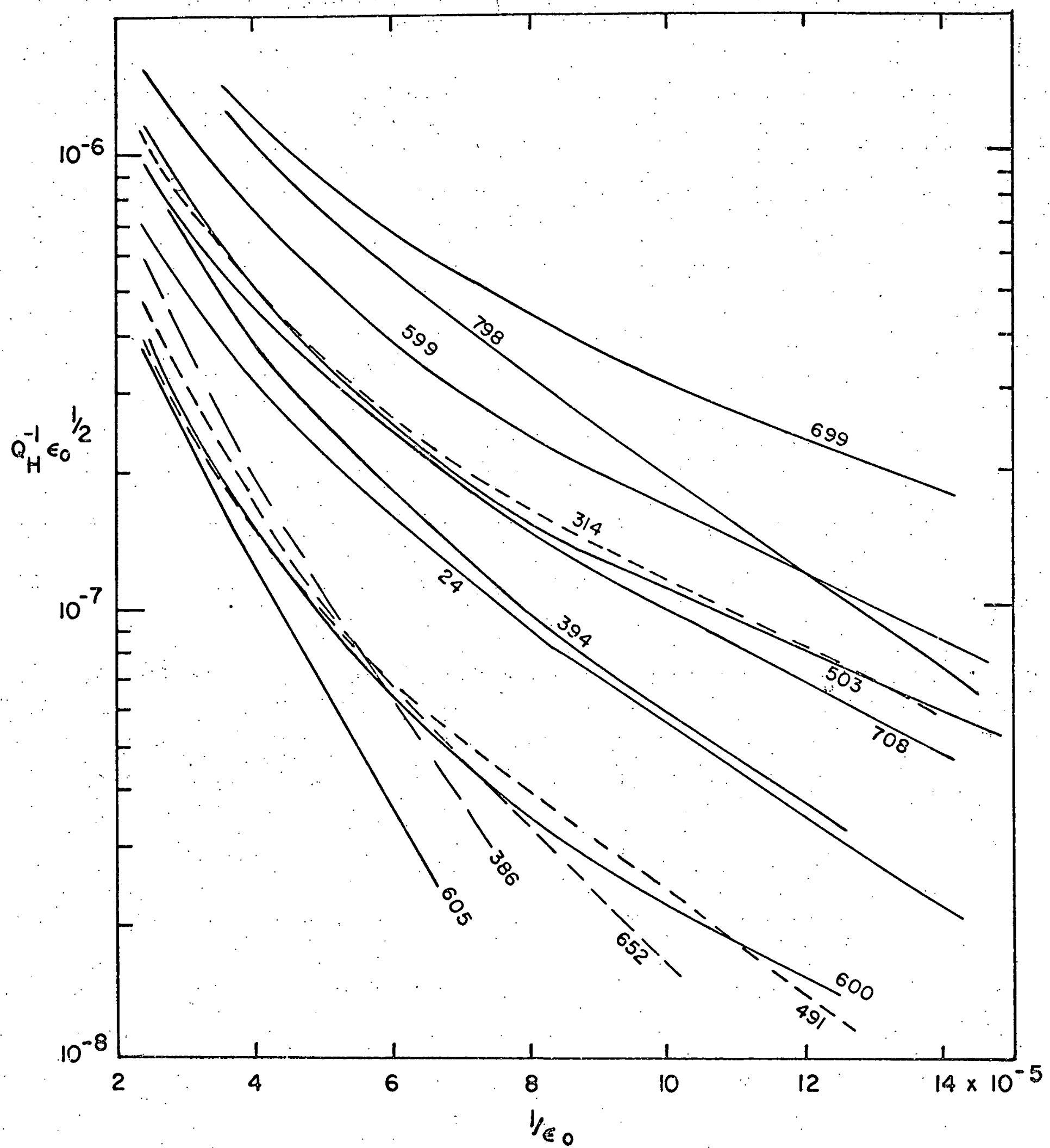




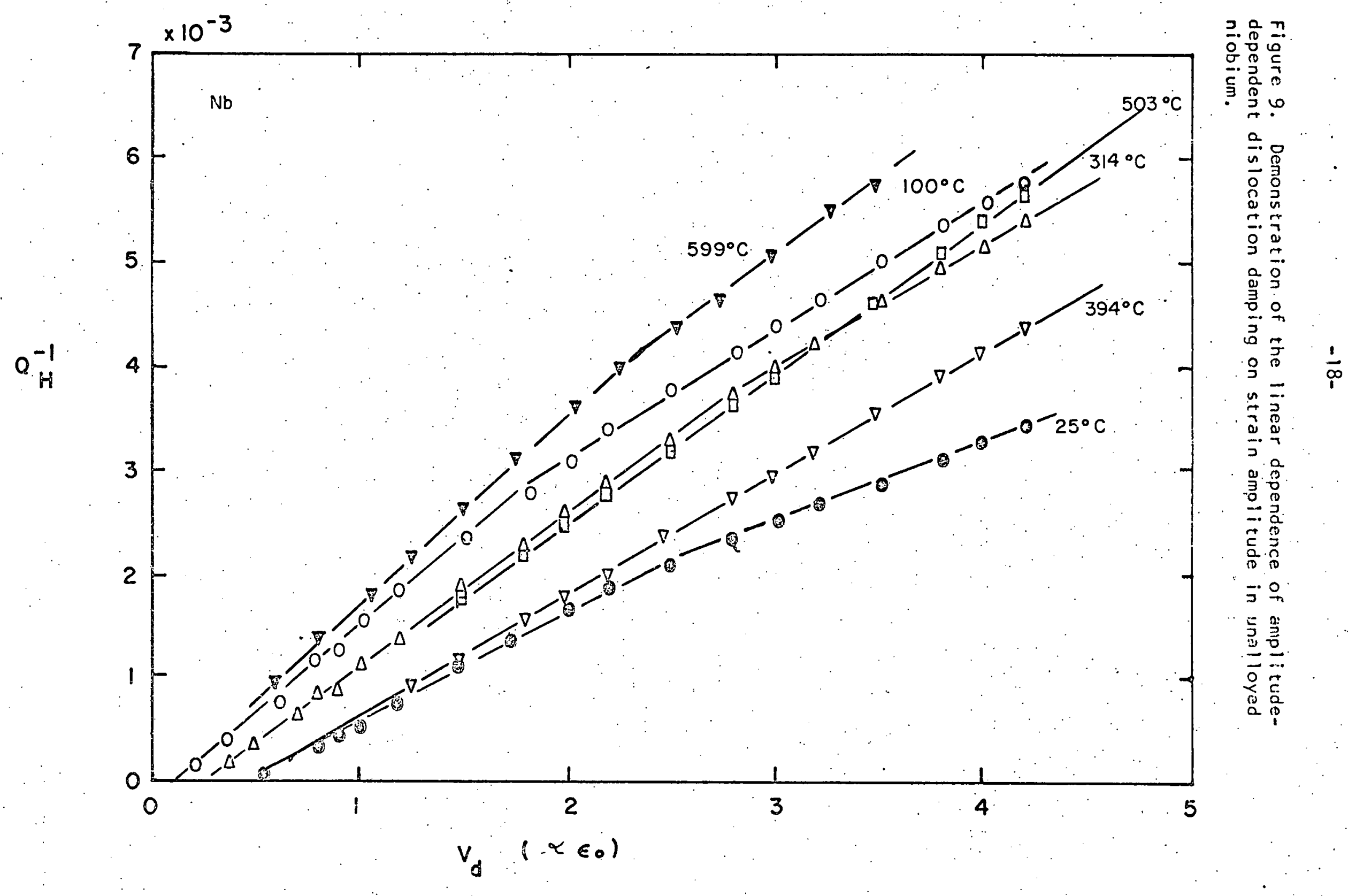

